\title{
GROWTH OF THE ORB WEAVER, ARANEUS DIADEMATUS, AND \\ CORRELATION WITH WEB MEASUREMENTS*
}

\author{
By Jay Benforado and Kent H. Kistler \\ Division of Research, North Carolina Department of Mental Health \\ Raleigh, North Carolina 276I I
}

\section{INTRODUCTION}

It is a well-known fact that within any population of spiders of similar age there is considerable variation in the size of individual spiders of the same species. In literature as early as I89o, McCook has observed this variation and repeated observations (Comstock, I940; Savory, I928) have verified this phenomenon. Although observations are frequent, explanations are few. Bristowe (1958) cites differences in feeding as a reason for differential size, but the reference is made merely in passing and to the authors' knowledge is not elaborated upon elsewhere. This paucity of explanation lends itself to further analysis of the factors contributing to the phenomenon of differential size.

Our purpose in this paper is to isolate some of the factors which contribute to differential size in Araneus diadematus Clerck (for identification of species, see Levi, I97 I), and to elaborate upon certain of these factors as we are able.

Corresponding with differential size, in an orb-weaver such as Araneus diadematus, differential growth is also manifested in changing dimensions of the web. That large differences in dimensions exist betwen the individual webs of spiders is also a well-known fact. An attempt to clarify some of the factors influencing web changes is also made.

\section{METHOD}

environment: The spiders used were from two cocoons of Araneus diadematus, obtained from Canastota, New York, which hatched on April 26, 1972. From the time of hatching and throughout the experiment, the spiders were kept in a room which was lighted 16 hours per day aand kept cool during the eight dark hours by an air conditioner. (See Witt, 197 I).

EARLY REARING: At the time of hatching, the offspring from each

* Manuscript received by the editor March 1, 1973 
cocoon were placed in a separate rearing box. The spiderlings were kept in these boxes, living on a communal web with a constant supply of loose gnats in the box, until they began to build individual webs approximately three weeks after hatching. As each animal built her first web she was removed from the rearing box and placed in an individual glass tube, approximately I $\times 7 \mathrm{~cm}$, with the ends of the tube stoppered with cotton. From the time the animals were placed in the tubes until onset of the experiment they were fed approximately IO-I 5 gnats per week, by placing the gnats in the tube with the spiderling. The animals were watered by wetting the cotton with water daily.

DISTRIBUTION: Seven weeks after hatching the two sets of spiderlings were each separated into three equal groups by means of a random numbers chart. No attempt was made to distribute males and females evenly. Although the growth (body weight) of males and females differs, it has been shown that the early growth of both sexes is alike (Witt et al., I972). Because of the short duration of the experiment and the difficulty in identifying male spiders before the last molt, distribution of males and females was left to chance.

At the time of initial grouping the two sets of spiderlings numbered twenty and thirty respectively. It was decided to feed each of the three groups of each set according to a different feeding schedule: one group every day, one group twice weekly, and one group every ten days. Thus there were six groups, one for each set of offspring on each feeding schedule. After one week of this procedure, however, it was decided because of the small size of the groups to reduce the number of schedules to two, and the middle schedule was dropped and its members distributed randomly between the lighter and heavier-fed groups.

Data for animals that died or escaped during the course of the experiment were removed, so figures represent only animals observed for the duration of the experiment.

WEIGHING: Each spider in the heavy-fed groups was weighed once a week, to O.I $\mathrm{mg}$, while animals in the light-fed groups were weighed on the day of feeding and the day after feeding.

WEB ANALYSIS: After eleven days of controlled differential feeding in the tubes, the spiders were transferred to aluminum and glass laboratory cages, $50 \times 50 \times$ ro $\mathrm{cm}$. At this time the animals were eight weeks old. From this time on the spiders began to build webs. Photographs of webs were taken daily and analyzed (Reed et al., I965). Daily records of web building were kept and the webs were 


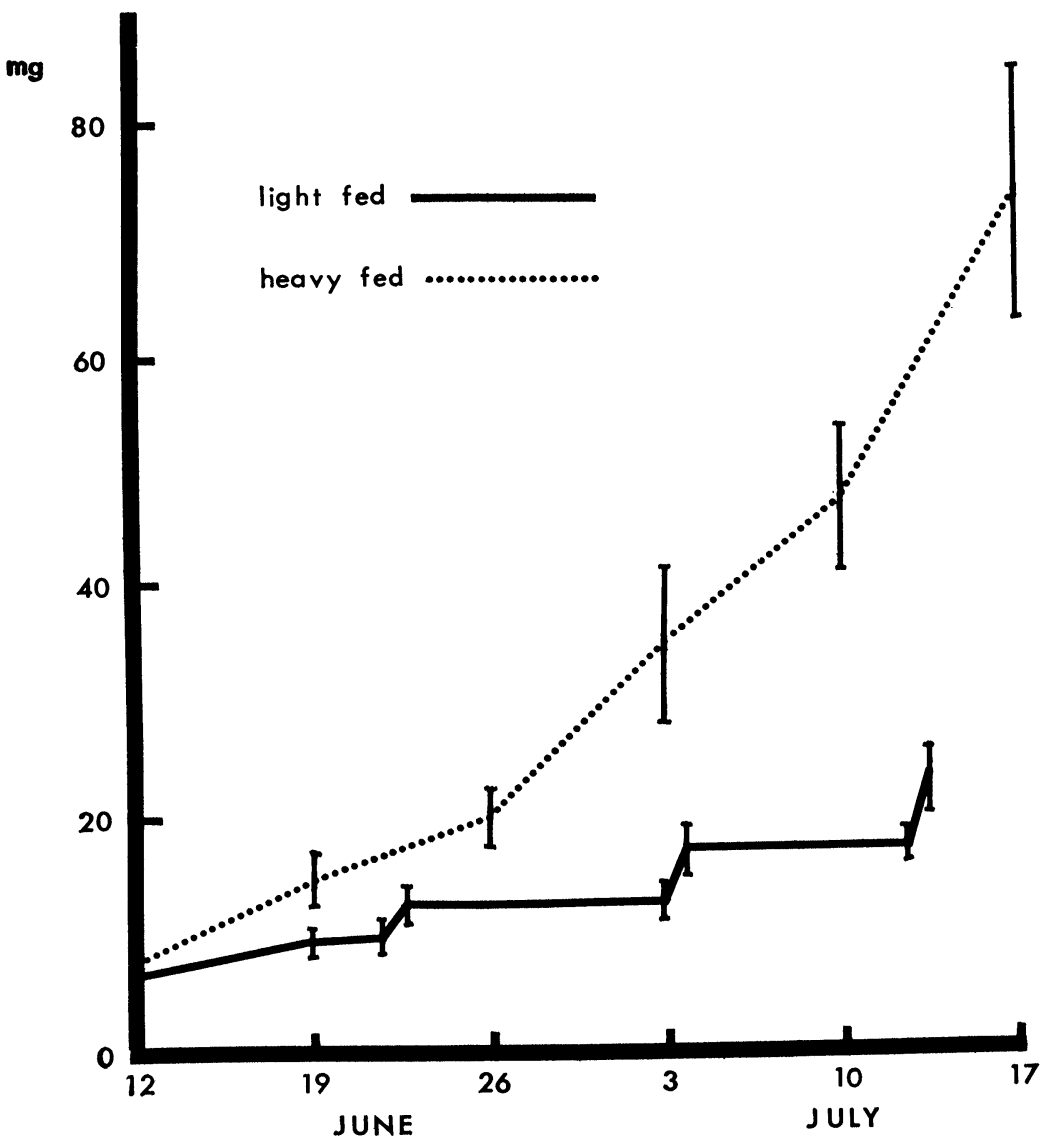

Figure 1. Mean weights of 19 light-fed and 15 heavy-fed Araneus diadematus with standard errors (vertical lines). Figures are for both sets of spiderlings combined. Sharp increases in weight in the light-fed group are due to the animals being weighed before and after feeding. Note the increasing difference in weight between the light-fed and heavyfed group. 
destroyed daily with the thread left in the cage for the spider to digest.

FEEDING: While in the tubes, the spiders were fed by placing a previously weighed de-winged housefly in the tube daily or every ten days. Those spiders that would not eat a housefly had three to seven unweighed gnats placed in their tube. By visual inspection the following day it was determined whether the fly had been eaten. The remains of the eaten flies were then weighed to obtain an approximation of the amount eaten by each spider. The spiders were watered by wetting the cotton every other day.

After being placed in the cages, if the spider had a web, feeding was by means of placing the housefly in the web; if there was no web, we attempted to induce the animal to eat by placing the fly in front of its mouth. The heavy-fed spiders were offered at least one fly per day and more, if they would accept it. The light-fed group was fed one fly once every ten days. If on the day of feeding of the light-fed group a spider would not eat, a note was made and the attempt repeated until successful. All spiders were watered on Mondays, Wednesdays and Fridays by spraying a small amount of water in each cage.

MoLTS: From the onset of the experiment molts were recorded by date of the molt to give an indication of the maturation of the animal.

\section{RESULTS}

FEEDING AND WEIGHT INCREASE: At the end of a period of five weeks the two feeding schedules resulted in two significantly different weight groups. This development is shown in Figure I, which illustrates the increasing difference in weight between the two groups. At the onset of differential feeding the mean weights of the two groups were alike, however, a T-test between the mean weights at the end of the experiment is significant at the $0.1 \%$ level.

An analysis of covariance was performed on the data. Because the original data was non-homogeneous, a transformation $[\log (x+$ Io)] was made (Winer, I962). The initial observation was used as a covariate in the analysis of covariance. Because the analysis of covariance indicated no significant difference in the behavior (growth) of the two families, all figures are for both families combined. For the heavy-fed group the mean weight changed from 7.93 $\mathrm{mg} \pm \mathrm{I} . \mathrm{O} 4$ on June 12 to $74.28 \mathrm{mg} \pm 10.93$ on July I7. The mean weight of the light-fed group changed from $6.40 \mathrm{mg} \pm 0.98$ 
on June $\mathrm{I} 2$ to $\mathrm{I} 7.9 \mathrm{I} \mathrm{mg} \pm 2.56$ on July I 3 ; there was a significant interaction between time and feeding schedule below the $1 \%$ level. FEEDING AND MATURATION: If the number of molts over time is taken as an indication of speed of maturation, then a relationship between feeding and rate of maturation can be seen. During the period of differential feeding the number of molts of the heavy-fed and light-fed groups differed significantly at the 5\% level. The heavy-fed group had a mean number of 3.0 molts while the light-fed group had a mean number of 2.3 molts. These results are in agreement with the findings reported by Deevey ( 1949) with Latrodectus mactans (Fabricius) and indicate that in the laboratory with only food quantity as a variable, a relationship exists between the rate of weight increase and the rate of maturation.

INITIAL WEIGHT AND RATE OF GROWTH: From the beginning of the experiment we noted a wide variation of weights of the individual animals. At the onset of differencial feeding individual weights ranged from I.I $\mathrm{mg}$ to $\mathrm{I} 6.2 \mathrm{mg}$. In both the light-fed and heavyfed groups there existed a positive correlation between initial weight and final weight. For the light-fed group $r=0.7713$ and for the

TABLE I

\begin{tabular}{|c|c|c|c|c|}
\hline \multirow[b]{2}{*}{ Measurement } & \multicolumn{2}{|c|}{ Light-fed } & \multicolumn{2}{|c|}{ Heavy-fed } \\
\hline & Early & Late & Early & Late \\
\hline Mean wt. (mg) of spiders & 12.52 & 22.30 & 20.14 & 59.34 \\
\hline Spiral area $\left(\mathrm{cm}^{2}\right)$ & I I 8.92 & I I $9.5 \mathrm{I}$ & I I 9.88 & I 38.32 \\
\hline Center area $\left(\mathrm{mm}^{2}\right)$ & 7 I I.OO & $877 \cdot 53$ & 920.30 & I 424.30 \\
\hline Thread length (m) & $7 \cdot 35$ & $7 \cdot 47$ & $7 \cdot 56$ & 8.47 \\
\hline Mesh width $\left(\mathrm{mm}^{2}\right)$ & 20.16 & 22.34 & 21.79 & 27.48 \\
\hline Angle regularity & 4.25 & $4 \cdot 16$ & $5 \cdot 52$ & 4.62 \\
\hline \# of oversized angles & I. 67 & I.87 & 2.50 & I. 80 \\
\hline $\begin{array}{l}\text { Relative deviation of } \\
\text { spiral turns (South) }\end{array}$ & 0.34 & 0.33 & $0.4 \mathrm{I}$ & 0.35 \\
\hline
\end{tabular}

Selected measurements of webs built by a group of light-fed and heavy-fed spiders. Because not all spiders built on the same day, early and late webs of both groups were chosen from two five day periods two weeks apart. Measurements are divided into those which measure size (above the broken line) and those which measure regularity. Note the difference between the light-fed and heavy-fed animals in measures of web size at the late date. While the heavy-fed group increased in all size measures (see Fig. 2), no web regularity measures changed. For an explanation of web measurements see Witt et al., A Spider's Web. 


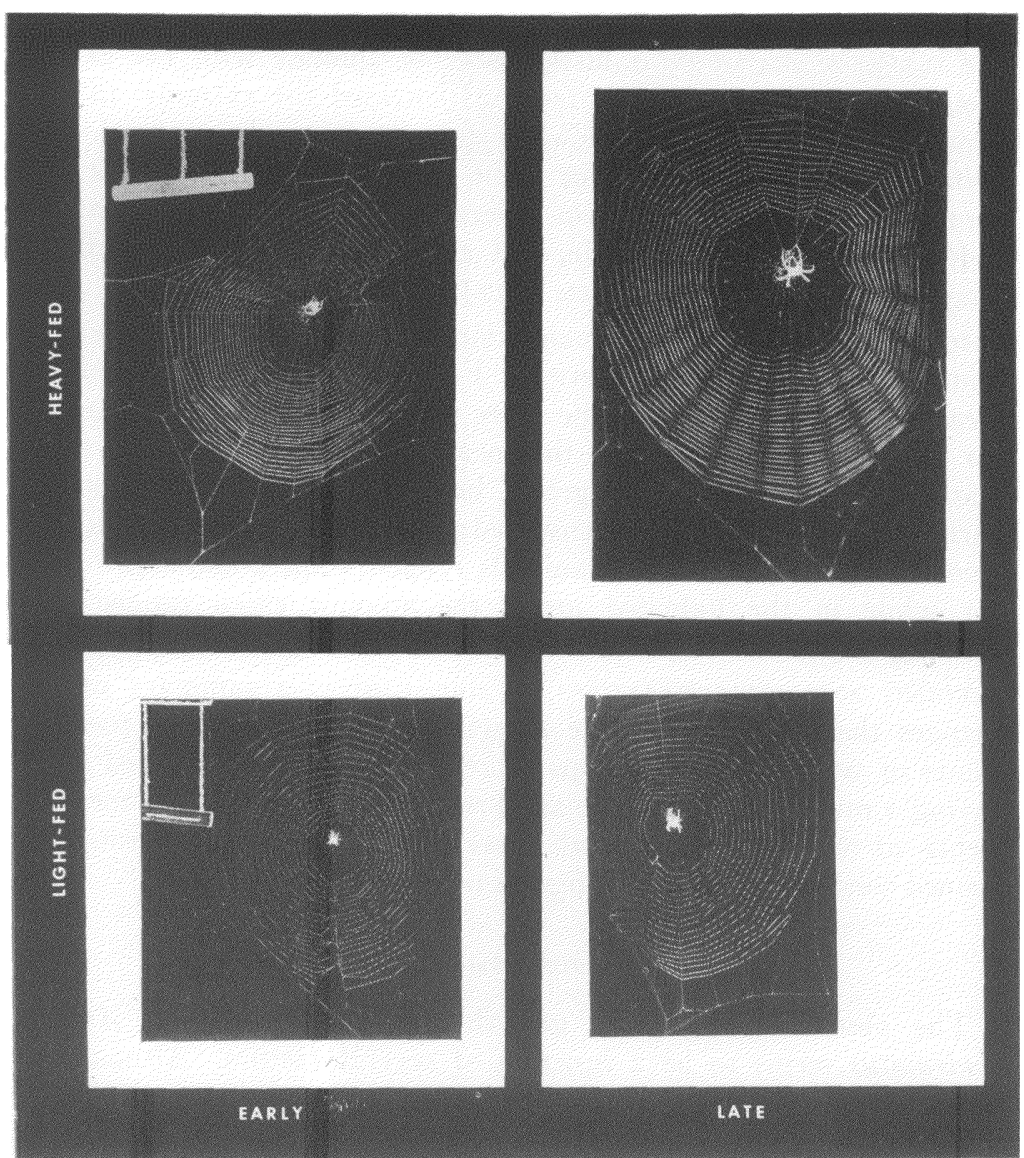

Figure 2. Selected web samples from two spiders: one heavily-fed spider and one light-fed spider. Webs are from the periods measured in Table 1 and are all reproduced to the same scale. Note that while both the heavy-fed and light-fed animals began with webs of similar size, after two weeks of differential feeding the large, heavy-fed spiders' webs had increased in size while the webs of the small, light-fed spiders remained the same size. 
heavy-fed group $\mathrm{r}=0.9 \mathrm{II}$; both correlations are significant at the $0.1 \%$ level. In most instances those animals with the extreme weights at the beginning of feeding remained the extremes in their group. Reasons for the variation in initial weight are unknown. Different rates of growth for light and heavy hatchlings have recently been shown to occur in several species of spiders, apparently independent of food available, and appear correlated with different lengths of life (Reed and Witt, 1972).

AMOUNT EATEN: An approximation of the amount eaten was obtained for a three week period. For nine heavy-fed animals the mean amount eaten during the three week period was II $5.8 \mathrm{mg}$ and for fifteen light-fed animals the mean amount for the same period was $35.0 \mathrm{mg}$. Within each group, however, there was an enormous variation in the amount consumed: in the heavy-fed group the amount eaten by individual animals ranged from $209.0 \mathrm{mg}$ to 42.6 $\mathrm{mg}$ while in the light-fed group the amount eaten ranged from $49.6 \mathrm{mg}$ to 3 gnats weighing $18 \mathrm{mg}$.

FEEDING AND WEB Changes: Table I gives a summary of web changes that accompanied the growth of the animals. In measurements of web size both groups increased, with the heavy-fed group having a much larger increase as illustrated in Figure 2. In measurements of web regularity both heavy-fed and light-fed groups remained constant, as shown in figures of Table $\mathrm{I}$.

\section{Discussion}

The observed differential growth and development in Araneus diadematus seems to be a function of several factors. Although an exposure to a greater than normal supply of food generally results in faster than normal growth and development, even within a group exposed to the same food supply there seems to be a great variation in growth rates. Evidence of these differences is expressed in the increasing standard errors in Figure $\mathrm{I}$, and seems to be dependent upon individual factors in the animals rather than environmental variations. Large differences in the amount eaten by individual animals in the laboratory existed and presumably exist in nature. These differences seem to correspond to differences in the rate of growth in agreement with the findings of Turnbull in other species of spiders (Turnbull, 1960, 1965). However, whether these differences in the amount of food eaten are due to differences in proficiency in prey-catching or to differences in appetite or some other factor in the animal is not clarified by our findings. 
Another important factor influencing differential growth is the initial weight of the animal. Variations in initial weights within a family are generally retained during the course of development. Although several possible reasons for different initial weights within a family have been given by others, the authors are reluctant to offer any explanations.

In an orb web weaving spider such as Araneus diadematus the amount of food available to the animal is roughly equivalent to the number of prey which become entrapped in the web. The number of prey entrapped in the web is in turn determined by a number of variables such as web-site, size and fine structure of the web, and frequency of web building. Thus, it can be seen that the interaction of the variables resulting in differential size and growth is complex and can be divided into those factors which influence the amount of food available to the spider and those factors which influence the spider's use of the food available to it.

Repeated attempts have been made to explain web characteristics in terms of characteristics of the individual spider (Peters, I936). More common, however, has been the notation of changes in the form of the orb web during the life of the spider (Tilquin, I942; Savory, I952) and the attempt to relate these changes to changes in the animal (Witt and Baum, I960; Witt, r963; Reed et al., i969). Because influencing factors vary concurrently, it is frequently difficult to assess the causes of changes in the form of the web.

In our experiment we attempted to isolate the effect of one variable (weight) while minimizing the effect of a variable which normally changes concurrently (time). All animals used hatched on the same date, however, one group (the heavy-fed) gained considerable weight over the period measured. The web changes accompanying these weight increases are summarized in Table I. Because all of the animals were hatched on the same date, we conclude that increases in web size are due to differences in size of the animals resulting from differential feeding rather than differences in age. If appetite were a factor influencing web size, it would appear that the hungrier, light-fed animals would build a larger web in an attempt to catch more food; however, this is not the case.

The relationship between food and the web of a spider is a delicate one. Without food, the spider's web-building ability diminishes, but without a web there is no food (Peakall, I968). Thus, like a businessman, the spider faces the law of diminishing returns. It appears that the hungry spider chooses to conserve its resources 
rather than gamble on a larger web trapping more food. Early food deprivation experiments (Witt, I963) show that the spider continues to build the same size web when deprived of food, but with less thread until finally a decreasing in web size occurs. Because our hungry (light-fed) animals were kept on a diet closer to a maintenance level than a deprivation level, we observed no decreases in web dimensions.

Feeding conditions in a natural environment vary more than those imposed in a controlled laboratory. Yet the spider is able to survive in these naturally diverse conditions because of its adaptability. In situations where there is little food available, the spider is able to survive by growing at a slow rate and maintaining the same size web. Where food is abundant, the spider takes advantage of the situation, growing at a fast rate and increasing the size of its web.

The spider has developed a method for coping with a wide range of feeding conditions. By varying its body and web growth, the spider can survive under the diverse conditions imposed by nature, thus minimizing the necessity of seeking new food supplies and relocating the web. Our findings provide new insight into the spider as an example of an animal that adapts itself successfully to its environment.

\section{SUMMARY}

Spiders from two cocoons of Araneus diadematus were exposed to five weeks of two different feeding schedules: one group was offered large amounts (one housefly per day) of food, the other group scarce (one fly every ten days) amounts. Although both groups increased in weight, weight gains of the heavy-fed group were significantly greater than those of the light-fed group, regardless of cocoon origin. Within each group there was a wide variation in the growth of individual animals, indicating the presence of factors other than food supply; i.e. animals with extreme weights within a group at the onset remained the extremes.

In conjunction with increases in weight, over the three week period of observation, webs of the heavy-fed spiders showed an increase in size but not in regularity and shape in comparison to webs of the smaller, light-fed animals of the same age which did not change. Such data suggest an increased chance of survival of the species through variations in rate of growth and maturation dependent on environmental factors. 


\section{AcKNowledgements}

This work was carried out in the laboratories of the North Carolina Department of Mental Health and was supported by Grant Number GB 25274 from the National Science Foundation to Peter N. Witt. The authors gratefully acknowledge the assistance of Dr. Peter N. Witt during all stages and the assistance of Mrs. Mabel B. Scarboro during the period of laboratory work.

\section{References Cited}

Bristowe, W. S.

1958. The World of Spiders. Collins, London.

Comstock, J. H.

1940. The Spider Book. Revised and edited by W. J. Gertsch. Comstock, Ithaca, N.Y.

DeEveY, G. B.

1949. The development history of Latrodectus mactans (Fabr.) at different rates of feeding. Amer. Midland Naturalist. 42: 189-218.

LEVI, H. W.

1971. The Diadematus group of the orb-weaver genus Araneus north of Mexico (Araneae: Araneidae). Bull. Mus. Comp. Zool., 141: 131-179.

McCook, H. C.

1890. American Spiders and Their Spinningwork. Vol. 2, Published by the author, Philadelphia.

Peakall, D. B.

1968. The spider's dilemma. New Scientist, pp. 28-29.

Peters, H. M.

1936. Studien am Netz der Kreuzspinne (Aranea diadema.) 1. Die Grundstruktur des Netzes und Beziehungen zum Bauplan des Spinnenkörpers. Z. Morphol. Ökol Tiere, 32: 613-649.

Reed, C. F. And P. N. WitT

1972. Growth rate and longevity in two species of orb-weavers. Bull. Brit. Arach. Soc., 2 : 111-112.

Reed, C. F., P. N. Witt and R. L. Jones

1965. The measuring function of the first legs of Araneus diadematus Cl. Behavior, 25: 98-119.

Reed, C. F., P. N. Witt and M. B. Scarboro

1969. The orb web during the life of Argiope aurantia (Lucas). Develop. Psychobiology, 2: 120-129.

SAVORY, T. H.

1928. The Biology of Spiders. Sidgwick and Jackson, London.

1952. The Spider's Web. Frederick Warne and Co., London and N.Y.

TILQuin, ANDRÉ

1942. La Toile Géométrique des Araignées. Presses Universitaires de France, Paris.

Turnbull, A. L.

1960. Quantitative studies of the food of Linyphia triangularis (Clerck) (Araneae: Linyphiidae). Canad. Ent. 94: 1233-1249. 
Turnbull, A. L.

1965. Effects of prey abundance on the development of the spider Agelenopsis potteri (Blackwell) (Araneae: Agelenidae). Canad. Ent. $97:$ 141-147.

WiNer, B. J.

1962. Statistical Principles in Experimental Design. McGraw-Hill, N.Y. pp. 606-615.

WitT, P. N.

1963. Environment in relation to behavior of spiders. Arch. Environ. Health, 7: 4-12.

1971. Instructions for working with web-building spiders in the laboratory. BioScience, $21: 23-25$.

WitT, P. N. AND Ricarda BaUm

1960. Changes in orb webs of spiders during growth. Behavior, 16: 309-318.

Witt, P. N., J. O. Rawlings and C. F. Reed

1972. Ontogeny of web-building behavior in two orb-weaving spiders. Am. Zoologist, 12: 445-454.

Witt, P. N., C. F. Reed and D. B. Peakall

1968. A Spider's Web. Springer Verlag, Berlin. 

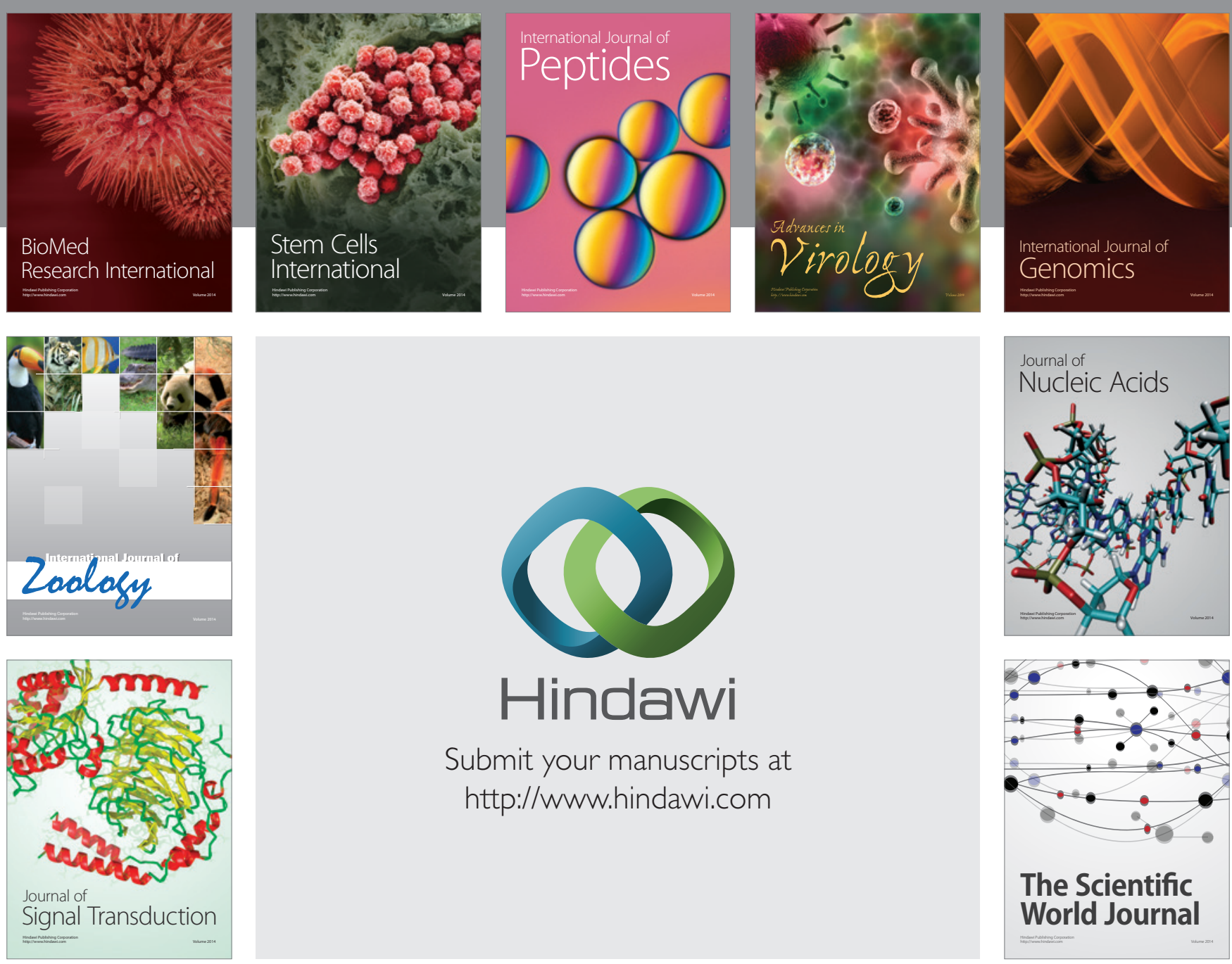

Submit your manuscripts at

http://www.hindawi.com
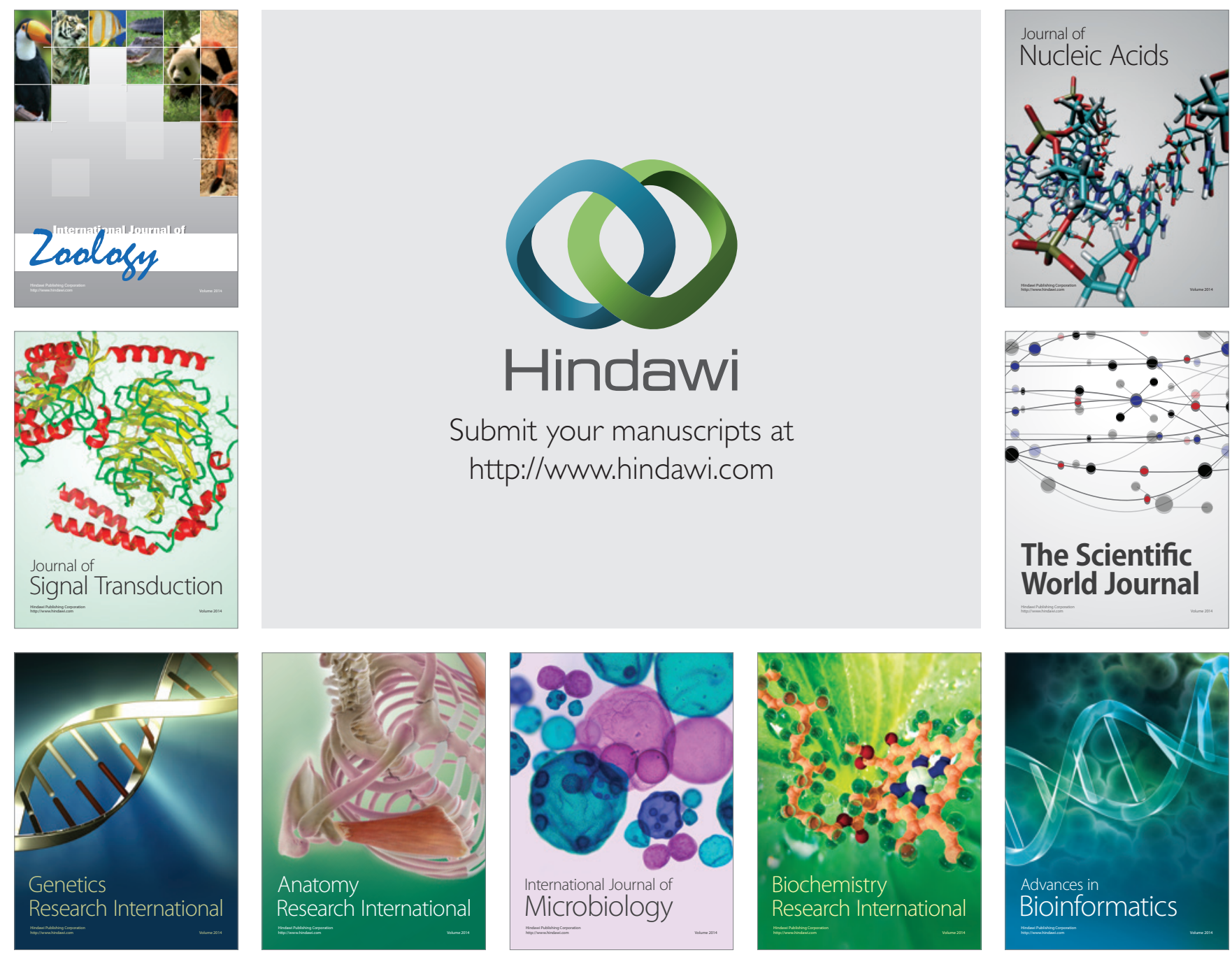

The Scientific World Journal
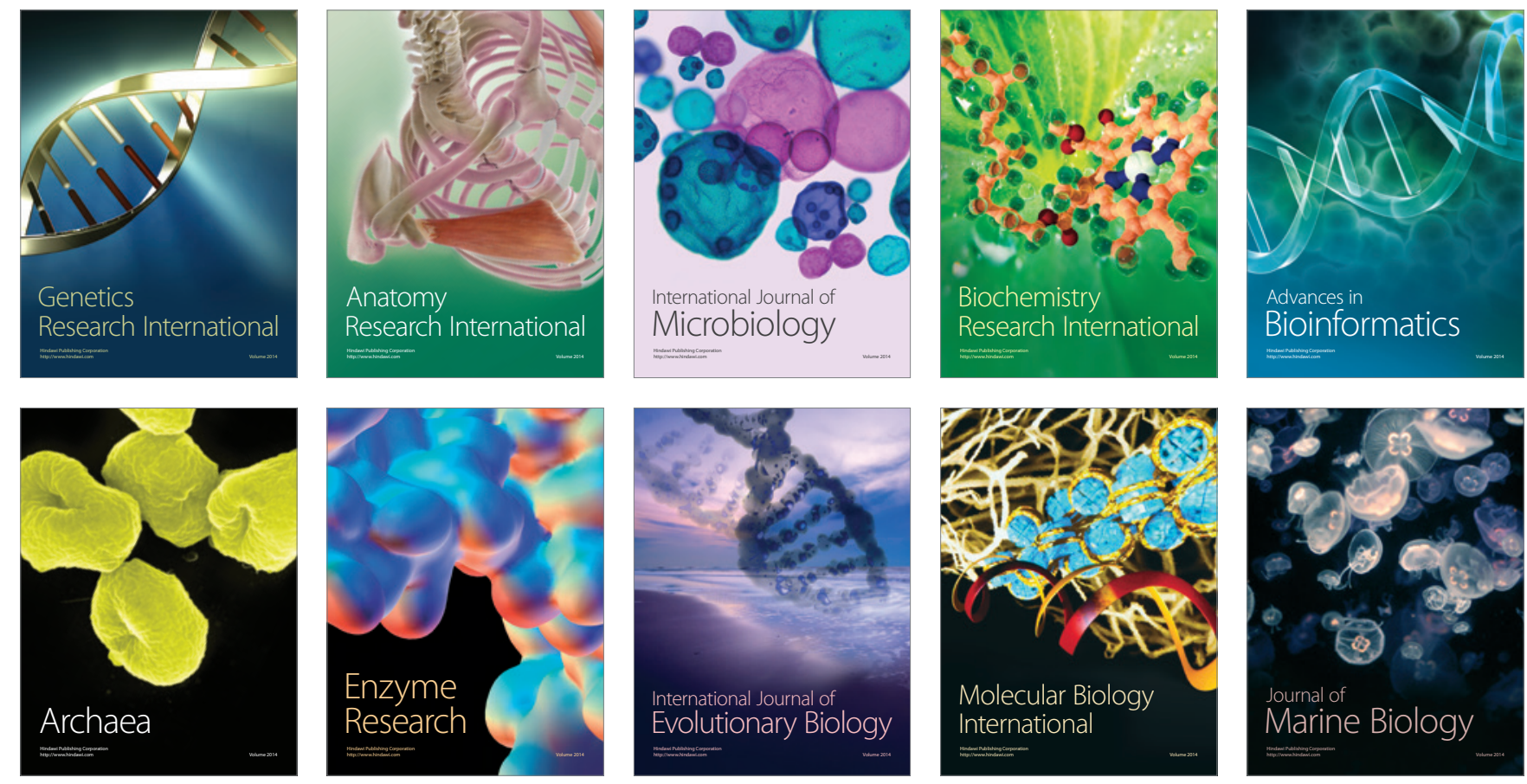